\title{
APLICAÇÃO DO JOGO “CORRIDA ATÔMICA” COMO INSTRUMENTO MOTIVADOR DA APRENDIZAGEM DE QUÍMICA EM UMA ESCOLA PÚBLICA DE VITÓRIA-ES
}

\author{
Sonara Gonçalves ${ }^{1}$, Glenda Firme ${ }^{2}$, Júlia Raquel Peterle Pereira ${ }^{3}$, \\ Claudinei Andrade Fimoleno ${ }^{4}$, Maria Geralda Oliver Rosa ${ }^{5}$ \\ Instituto Federal do Espírito Santo \\ Campus Vila Velha - Coordenadoria do Curso de Licenciatura em Química \\ Avenida Ministro Salgado Filho, S/№ - Bairro Soteco \\ CEP 29106-010 - Vila Velha - ES - Tel.: (27) 3149-0700
}

\section{RESUMO}

A fim de gerar situações que estimulem a aprendizagem dos alunos foi desenvolvido e aplicado em 7 (sete) turmas de 1ํano do Ensino Médio o Jogo Pedagógico "Corrida Atômica", em uma escola pública localizada em Vitória-ES. As metodologias utilizadas foram: aplicação de questionário, aulas teóricas, apresentação de vídeos, debates e confecção e aplicação do jogo, em um total de quatro aulas com duração de cinquenta e cinco minutos cada. 0 material utilizado na confecção do jogo foi cartolina e TNT, de baixo custo e fácil aquisição. Os alunos demonstraram grande entusiasmo em participar e também preocupação em dominar o conteúdo para responder corretamente as perguntas feitas ao longo do jogo.

Palavras-chave: ensino de Química, jogos, atividades lúdicas.

\begin{abstract}
In order to create situations that encourage student learning was developed and implemented in seven (7) classes of 1st year of High School the Pedagogical Game "Atomic Race" in a public school located in Vitoria-ES. The methodologies used were questionnaires, lectures, video presentations, debates and preparation and implementation of the game, in a total of four classes lasting fifty-five minutes each. The material used in making the game was cardboard and TNT, low cost and easy. Students showed great enthusiasm in participating and also concern in mastering content to correctly answer the questions asked throughout the game.
\end{abstract}

Keywords: teaching of chemistry, games, recreational activities.

\footnotetext{
${ }^{1}$ Aluna do curso de Licenciatura em Química, Ifes - Campus Vila Velha. E-mail: sonaragolcalves@yahoo.com.br

${ }^{2}$ Aluna do curso de Licenciatura em Química, Ifes - Campus Vila Velha. E-mail: glendafirme@hotmail.com

${ }^{3}$ Professora de Química, SEDU/ES - E-mail: juliapeterle@gmail.com

${ }^{4}$ Professor de Química, Mestre em Química, Ifes - Campus Vila Velha. E-mail: claudineiandrade23@gmail.com 5Professora das disciplinas de Formação Pedagógica, Mestre em Educação, Ifes - Campus Vila Velha. E-mail: mariageraldaoliver@hotmail.com
} 


\section{INTRODUÇÃo}

A Química é uma disciplina que faz parte do programa curricular do ensino fundamental e médio e sua aprendizagem deve possibilitar aos alunos a compreensão das transformações químicas que ocorrem no mundo físico de forma abrangente e integrada, para que os mesmos possam julgar, com fundamentos, as informações adquiridas na mídia, na escola, com pessoas, etc. A partir daí, o aluno tomará sua decisão e dessa forma, interagirá com o mundo enquanto indivíduo e cidadão (PCN, 1999). O retrato do ensino de Química em escolas públicas infelizmente é desanimador devido a vários fatores, como a falta de laboratórios e pouca base na área de ciências adquiridas no ensino fundamental (JUNIOR e SANTIAGO, 2009). É importante que haja comprometimento dos professores em tornar o ensino de química mais interessante, procurando amenizar as dificuldades encontradas pelos alunos por meio de atividades lúdicas em sala de aula como uma maneira eficiente de concretizar esse fato. 0 lúdico apresenta dois elementos que o caracterizam: o prazer e o esforço espontâneo, além de integrarem as várias dimensões do aluno, como a afetividade e o trabalho em equipe. (SOARES, 2005).

A atividade lúdica pode ser considerada um jogo se houver regras. De modo geral, os jogos sempre estiveram presentes na vida das pessoas, seja como elemento de diversão, disputa ou como forma de aprendizagem. Os professores podem utilizar jogos didáticos como auxiliares na construção dos conhecimentos em qualquer área de ensino e, se por um lado, o jogo ajuda os alunos a construírem novas formas de pensamento, desenvolvendo e enriquecendo sua personalidade, por outro, para o professor, o mesmo leva à condição de condutor, estimulador e avaliador da aprendizagem (CUNHA, 2012).

Esse trabalho teve como objetivo avaliar a aplicação de um jogo, denominado Corrida Atômica, no ensino do conteúdo "Atomística". O estudo foi desenvolvido como parte de um projeto maior e mais abrangente, cujo objetivo é a confecção e elaboração de jogos voltados para turmas do $1^{\mathrm{o}}$ ano do Ensino Médio, como forma de apoio na construção do conhecimento químico. 


\section{PROCEDIMENTOS METODOLÓGICOS}

A Corrida Atômica foi inspirado no jogo Ludo Atômico (OLIVEIRA e REGO, 2010) que foi apresentado no 8º Simpósio Brasileiro de Educação Química (SIMPEQUI). A aplicação do jogo, que foi modificado e adaptado para alunos do $1^{\text {o }}$ ano do Ensino Médio, seguiu uma metodologia de ensino que não se deteve apenas na aplicação do jogo e contou com aulas expositivas, exibições de vídeos e debates. Ludo é uma versão ocidental popular do jogo hindu Pachisi. É jogado por dois, três ou quatro jogadores (no caso de quatro, é possível formar duas duplas). 0 tabuleiro quadrado tem um percurso em forma de cruz e cada jogador tem quatro peões. Um dado define os movimentos. Os peões de cada jogador começam na base de mesma cor. 0 objetivo do jogo é ser o primeiro a levar seus quatro peões a dar uma volta no tabuleiro e a chegar no ponto final marcado com sua cor. Os peões movem-se pelo percurso no sentido horário (SOARES e CAVALHEIRO, 2006).

O jogo foi confeccionado com os seguintes materiais: tesoura, régua, cola quente, tinta de tecido branca, pincel, TNT preto (3x3 metros), folhas de EVA de quatro cores distintas (cores rosa, amarelo, verde e azul), cartolina dupla face de duas cores diferentes para montar o dado, cartolina dupla face preta para os cartões-pergunta e Contact para plastificar os cartões.

Foi feito um tabuleiro do jogo em forma de tapete de $3 \times 3$ metros a fim de fazer com que os alunos se tornassem as peças do jogo e pudessem participar ativamente da atividade. Em algumas casas do tabuleiro foram colocados pontos de interrogação para que, ao cair nessas casas, o aluno tivesse que responder perguntas sobre o conteúdo abordado anteriormente em sala de aula.

Para o jogo Corrida Atômica, foram feitas algumas alterações na forma de jogar para que todos os alunos pudessem participar da atividade. Cada turma foi dividida em quatro grupos onde cada um representava uma cor do tabuleiro. Cada grupo deveria indicar quatro jogadores para se colocarem nos círculos correspondentes a cor escolhida pelo grupo e o jogo começava quando algum grupo conseguia tirar o número 6 (seis) no dado. Um dos quatro jogadores de cada grupo arremessava o dado e andava a quantidade de casas sorteadas no dado. Se um aluno parasse em uma casa com um ponto de interrogação ele deveria escolher um cartão e responder a pergunta contida no mesmo. Caso o aluno não soubesse responder a pergunta, o mesmo poderia trocar de lugar com um dos três alunos, o qual deveria tomar seu lugar no jogo e responder a pergunta. Em nenhum momento do jogo os outros participantes 
poderiam falar a resposta para o aluno que estava no tabuleiro, sob a pena de desclassificação do grupo. 0 aluno, ao responder a pergunta, deveria seguir a punição ou bonificação descrita na carta por ter errado ou acertado a resposta da questão (ex. volte uma casa; fique uma vez sem jogar; avance duas casas). Assim que todos os quatro alunos do tabuleiro tivessem participado do jogo, mesmo que a rodada ainda não tivesse acabado, eles poderiam dar lugar a outros alunos para que todos participasse da atividade. Vencia o grupo que chegar primeiro a casa central do tabuleiro.

\section{RESULTADOS E DISCUSSÃo}

A comunicação da utilização dessa nova metodologia aos alunos foi recebida com grande aceitação e os alunos participaram ativamente das atividades propostas. Notou-se que os alunos buscaram aprender mais sobre o assunto e discutí-lo com a professora a fim de estarem preparados no momento da aplicação do jogo, inclusive pesquisando sobre o assunto em casa. 0 jogo foi aplicado em forma de teste, onde os alunos deveriam, sem a ajuda de nenhum outro aluno, responder as perguntas do jogo, como se fosse uma avaliação oral dos conhecimentos adquiridos. Grande parte dos estudantes responderam corretamente as questões propostas e, além do conhecimento adquirido, demonstraram um excelente trabalho em equipe e se mostraram preocupados em deixar que todos os alunos participassem do jogo. Mesmo sendo uma atividade avaliativa, na qual foram atribuídos pontos de participação, os alunos enxergaram a atividade como uma competição, cujo objetivo era ver quem sabia mais o conteúdo. Os alunos demonstraram mais segurança ao responder as perguntas, uma vez que a avaliação não se assemelhava a uma avaliação formal. A satisfação dos alunos, tanto pela diversão proposta como por terem conseguido assimilar o conteúdo, ficou evidente ao final da aplicação da atividade. A aplicação do jogo bem como a confecção do mesmo podem ser verificada segundo as figuras 1 a 5 , apresentadas a seguir: 


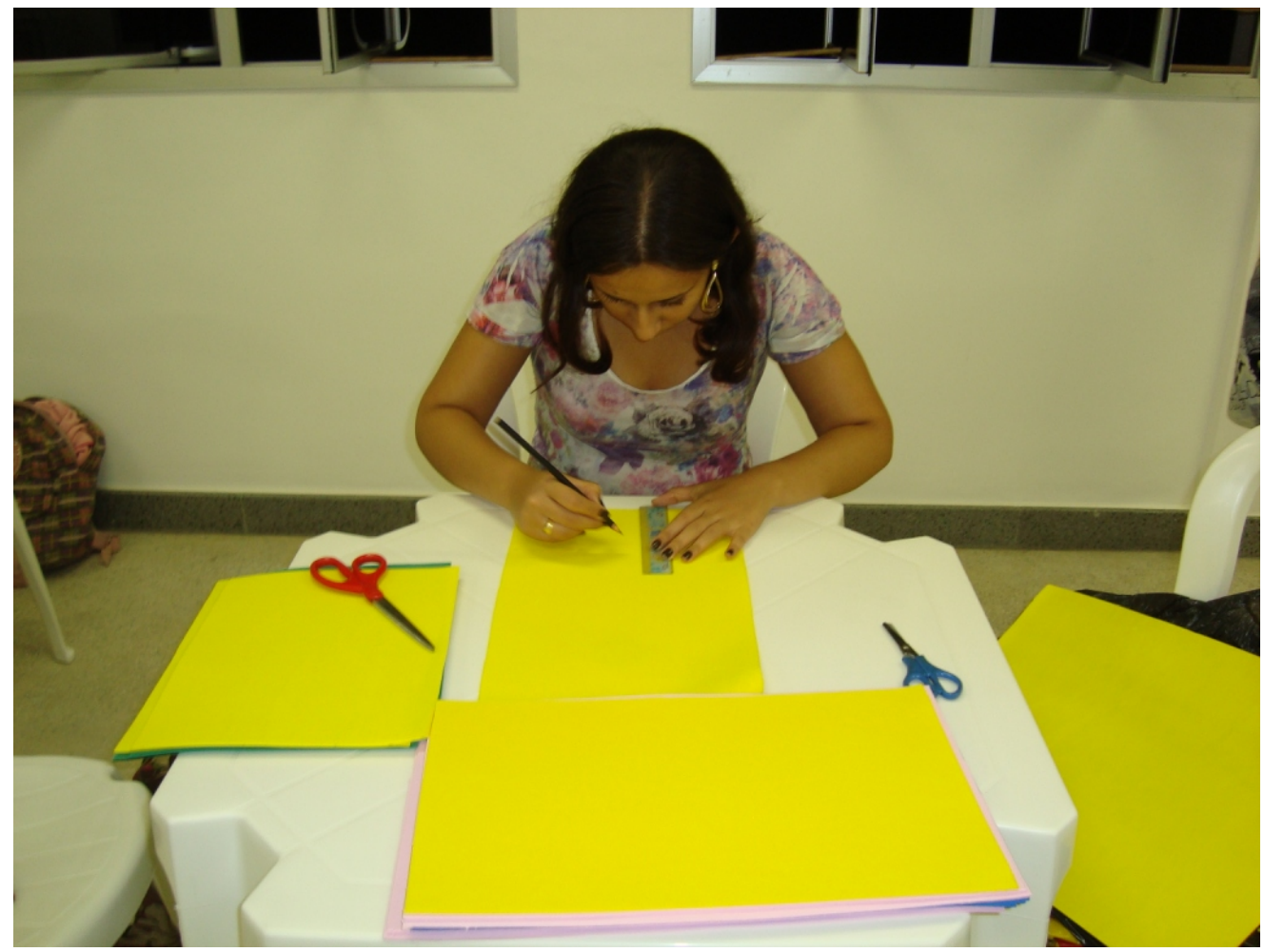

Figura 1: Confecção do jogo.

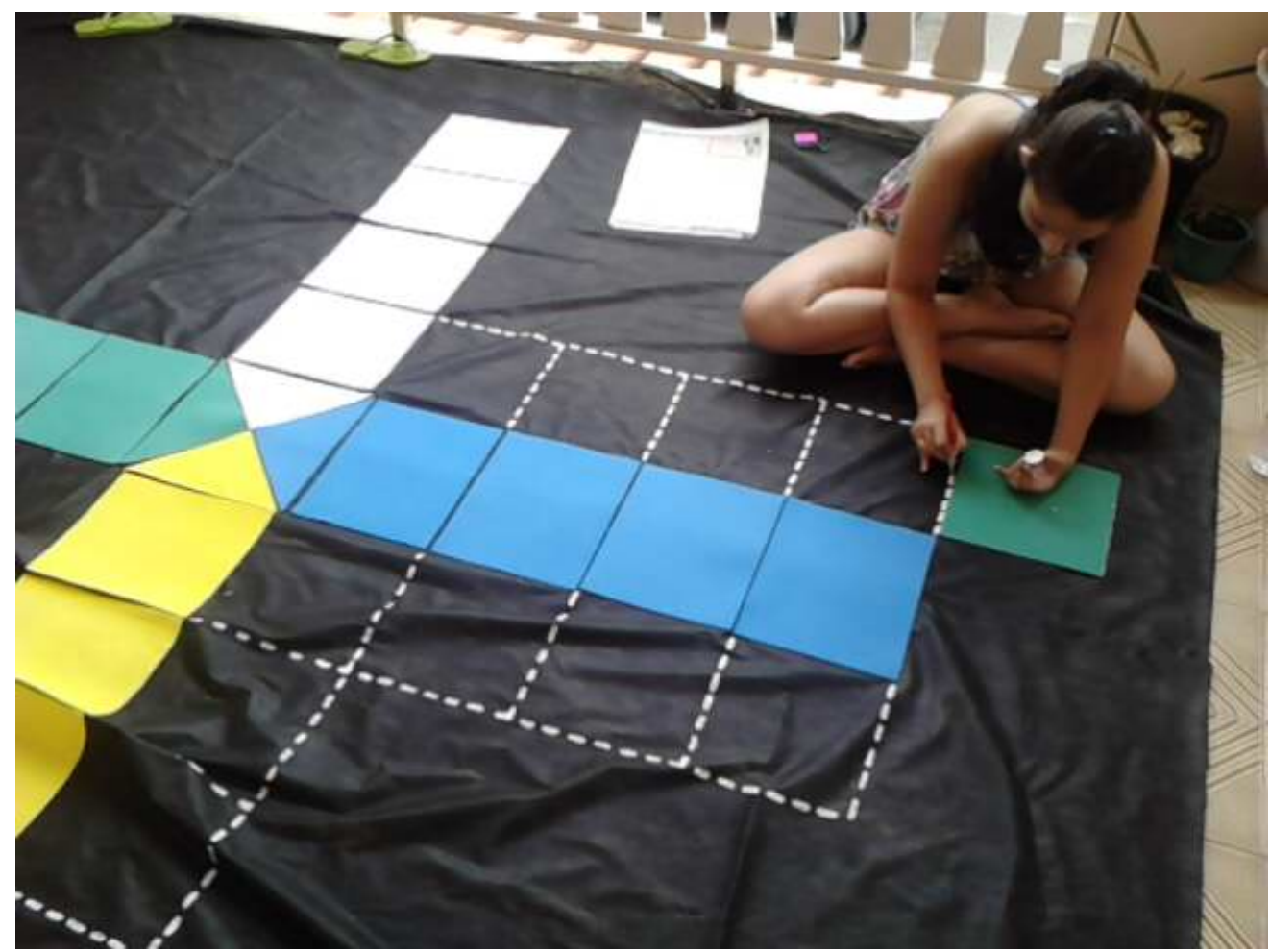

Figura 2: Confecção do tapete para o jogo. 


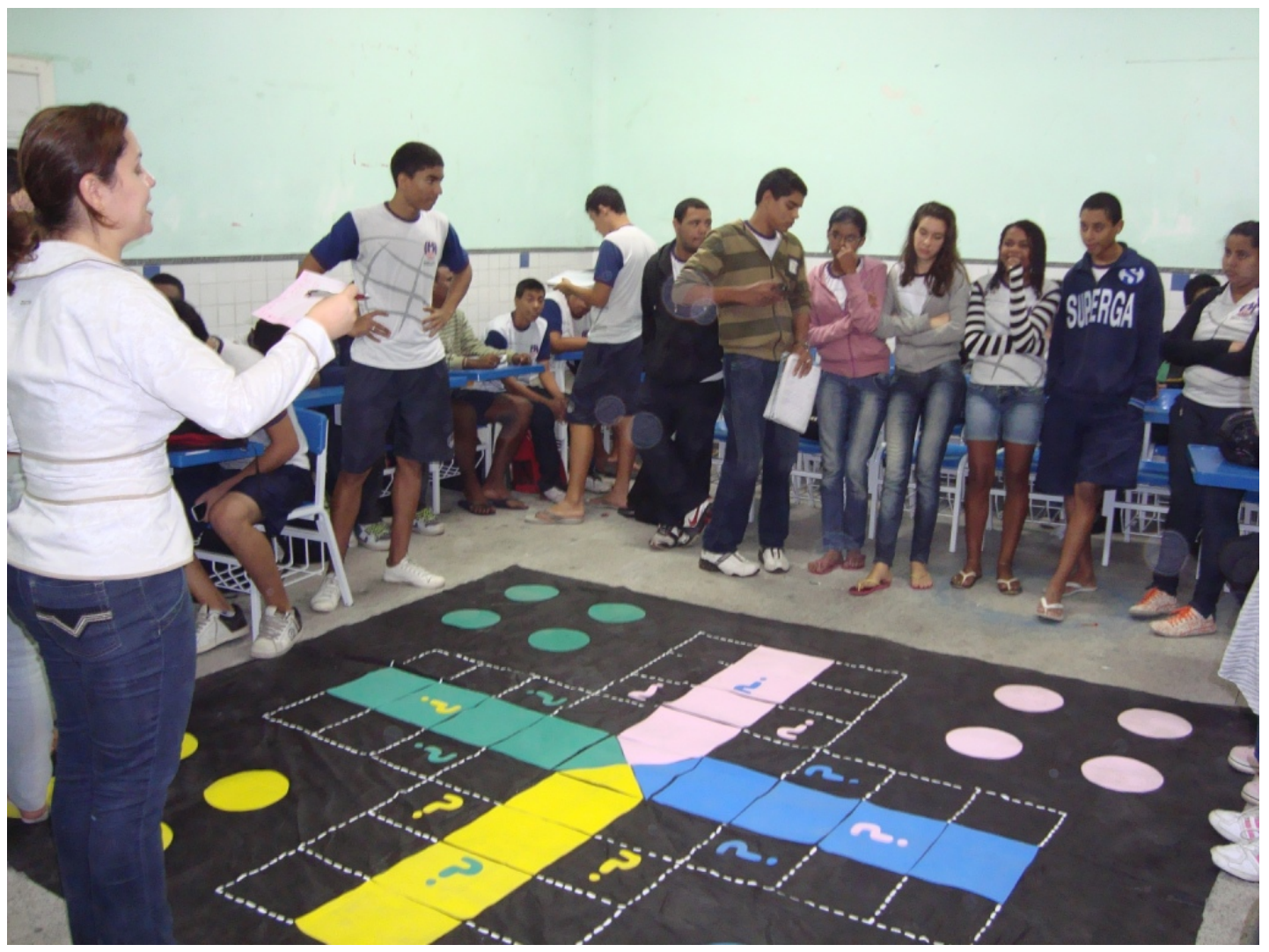

Figura 3: Aplicação do jogo - Explicação das regras para os alunos

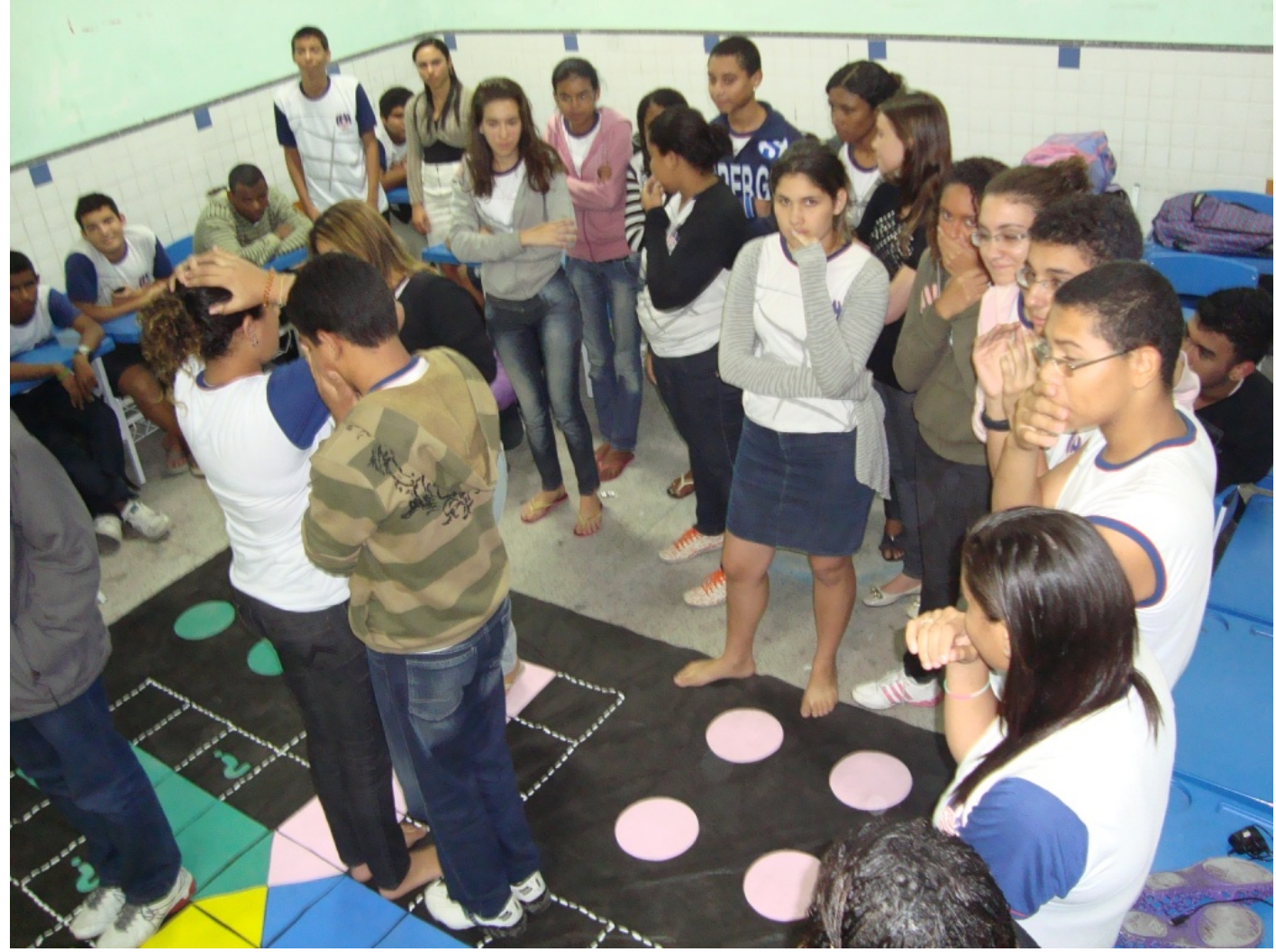

Figura 4: Aplicação do jogo - Alunos participando da atividade 


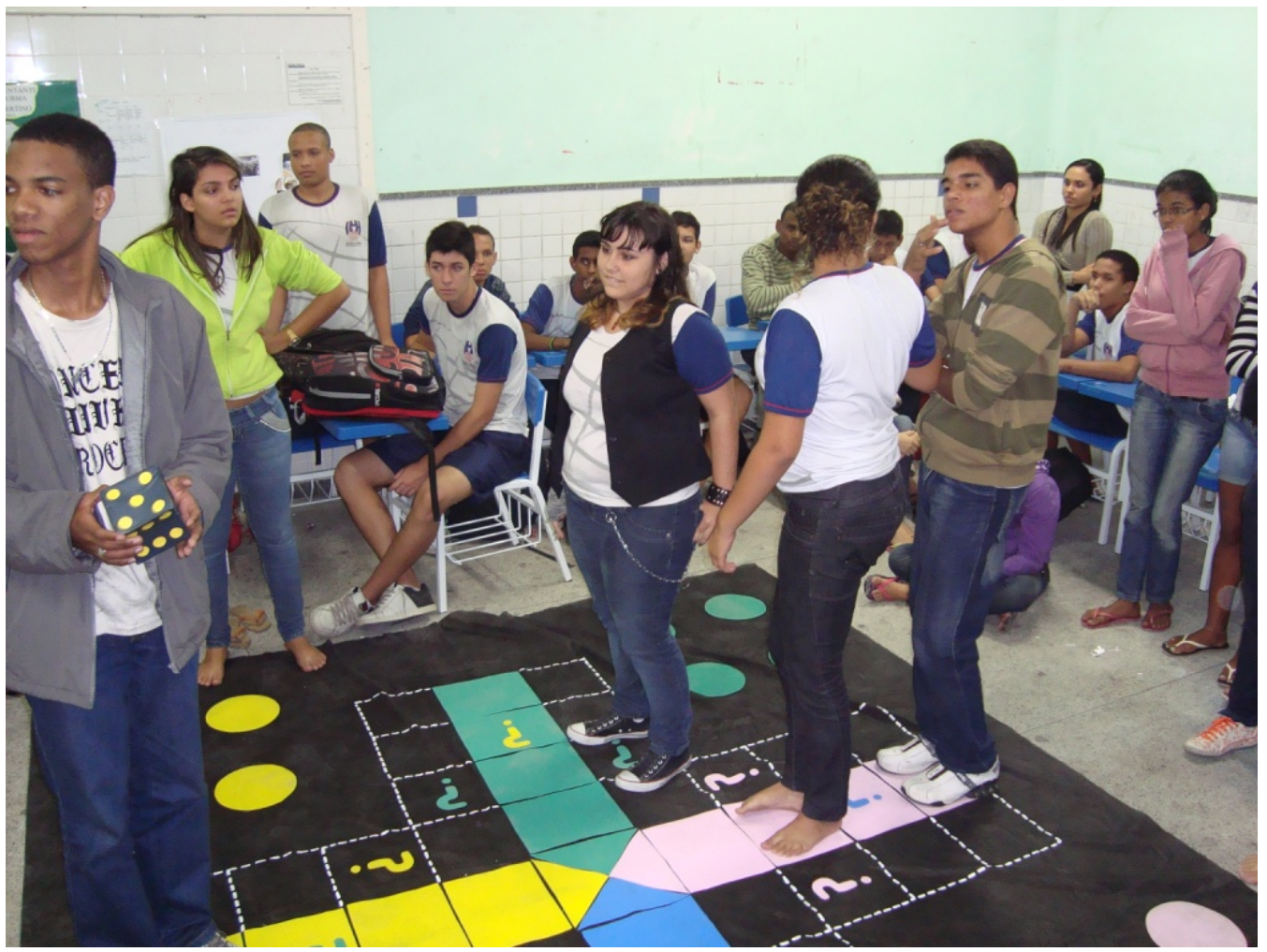

Figura 5: Aplicação do Jogo Pedagógico - Alunos da Escola Pública participando da Atividade Pedagógica.

Verificamos que a introdução de novas metodologias no ensino da química, com a introdução de atividades lúdicas de ensino, certamente aumenta a compreensão dos alunos e derruba as barreiras e o preconceito para com a disciplina, promovendo uma melhor aprendizagem do conteúdo e estimulando a interação entre os alunos. É importante ressaltar que o jogo foi doado para a Escola para que possa ser utilizado posteriormente nas próximas turmas de $1^{\text {o }}$ ano do Ensino Médio.

\section{CONSIDERAÇÕES FINAIS}

A utilização do jogo Corrida Atômica foi de grande importância para despertar a motivação dos alunos, visto que ele serviu como apoio, principalmente para a revisão de conteúdos. Nas aulas "tradicionais" os alunos demonstravam pouco interesse pela "Atomística" e com a aplicação do jogo eles passaram a participar mais ativamente das aulas, além dele ter favorecido o trabalho em equipe e a socialização entre os participantes. É importante salientar que o jogo foi confeccionado com materiais simples e de baixo custo e que a aplicação do jogo tornou mais dinâmica o processo de ensino e aprendizagem da Química. 


\section{AGRADECIMENTOS}

Os autores agradecem o apoio do Instituto Federal do Espírito Santo, da Secretaria de Estado da Educação do Estado do Espírito Santo, e ao PIBID/CAPES de Química do Ifes.

\section{REFERÊNCIAS}

CUNHA, M.B. Jogos no Ensino de Química: Considerações Teóricas para sua Utilização em Sala de Aula. Revista Química Nova na Escola, v. 34, n. 2, p. 92-98, 2012.

JUNIOR, C.O.S.; SANTIAGO, E.C.A. Deficiências no ensino-aprendizagem de química, física e biologia em uma escola estadual de Manaus. In: REUNIÃO ANUAL DA SBPC, 61, 2009, Manaus. Anais eletrônicos... São Paulo: SBPC/UFAM, 2009. Disponível em: http://www.sbpcnet.org.br/livro/61ra/resumos/resumos/6537.htm.

OLIVEIRA. L.M.S.; REGO, F.W.R. Desenvolvendo jogos didáticos para o ensino de química. In: SIMPÓSIO BRASILEIRO DE EDUCAÇÃO QUÍMICA, 8, 2010, Natal. Disponível em: :http://www.abq.org.br/simpequi/2010/trabalhos/189-7616.htm.

PARÂMETROS CURRICULARES NACIONAIS (PCN) - Ensino Médio; Ministério da Educação, 1999.

SOARES, M.H.F. O Lúdico em Química: jogos e atividades aplicados ao Ensino de Química. 2005. Tese (Doutorado em Química) - Instituto de Química, Universidade de Santa Catarina, Florianópolis, 2005.

SOARES, M.H.F.B., CAVALHEIRO, E.T.G. O Ludo como um jogo para discutir conceitos em Termoquímica. Revista Química Nova na Escola, n² 23, pag. 28, 2006. 